\title{
The Impact of Responsible Leadership (RL) on Responsible Employee (RE): The Mediating Role of Sustainable Leadership (SL)
}

\author{
Safaa Shaaban ${ }^{1}$ \\ ${ }^{1}$ The British University in Egypt (BUE), Egypt \\ Correspondence: Safaa Shaaban, The British University in Egypt (BUE), Egypt. El Sherouk City - Cairo - Suez \\ Desert Road, Postal No. 11837 - P.O. Box 43, Egypt. E-mail: safaa.shaban@bue.edu.eg
}

Received: May 31, 2020

doi:10.5539/ijbm.v15n9p75
Accepted: July 2, 2020

Online Published: August 16, 2020

\begin{abstract}
Business leaders are facing an uncertain issue regarding what extent their actions and decisions are responsible for the sustainable development supported by Responsible Employees. Although, several papers are discussing the concept of Responsible Leadership (RL) and Sustainable Leadership (SL). However, there is still an important missing element connected to these two leadership approaches which are Responsible Employee/s (RE). The purpose of this paper is to explore how Responsible Leadership and Sustainable Leadership affect Responsible Employees (RE). The study will examine the impact of two leadership approaches on RE. A sample of 250 employees and future leaders' positions working in the 18 factories and companies located in Egypt responded to a four parts questionnaire measuring research variables (Responsible Leadership, Sustainable Leadership and Responsible Employees). This study applies statistical analysis using SPSS, regression analysis, correlation, and structure equation module applied for this study. The finding of this study shows that Sustainable Leadership fully mediates the relationship between Responsible Leadership and Responsible Employees.
\end{abstract}

Keywords: responsible leadership and sustainable leadership, responsible employees, mediation

\section{Introduction}

The new challenge for today's organisational leaders is to successfully guide their organisations through volatile economic times and deal with the topic of sustainability (Fable et al., 2005). Sustainability goals in the Egyptian factory industry are not only narrowly focused on the traditional style of the time, cost and quality management, but also giving more attention to sustainable elements such as responsibility on the level leaders and employees, environmental, organisation's profitability and social development (Yılmaz and Bakış, 2015). The big challenges for organisations are leaders and employees; for organisations to be able to implement their sustainability strategies, they have to make sure those who implement this suitability strategy are responsibly and sustainably oriented leaders supported with responsible and sustainable employees.

However, when sustainability issues are delivering unusual practices of the business industry organisation in Egypt, this generates uncertainty for leaders (Demaid and Quintas, 2006). This is because leaders in the factory industry are still not convinced with the ability and credibility of sustainability in their management practices inside their organisation and its impact on the organisation performance. Though sustainability has targeted business activity implantation, they are not directly related to the organisation strategy generally and management and leadership specifically (Pakir, et al., 2012). The influences of sustainability and Responsible Leadership are still vague among industry leaders in Egypt; furthermore, there is a total lack or absence to define the Responsible Employees in the business industry. Sustainable leadership and responsible leadership both are important to the suitability. Responsible leadership (RL) is recognised by its holistic approaches, which include balancing various different levels and elements as personal, individual, organizational, community (Shaaban, 2019), while another writer mentioned that it is included in different elements like people, organisation's, leaders and followers, profitability and environment towards organizational performance (Avery \& Bergsteiner, 2011).

When it comes to the concept of Responsible Employee, this paper brings this element as a new element to the work or responsibility and sustainability. This paper discussed the phenomena of Responsible Employees as one of the most important elements to make sure that sustainable strategy should be implementing throughout Responsible and Sustainable Leadership and leaders. However, without Responsible and Sustainable Employees there will be a clear smooth implementation of these two leaderships and Sustainable Leadership. 
The objectives of this study are to test the impact of Responsible Leadership and Sustainable Leadership on Responsible Employees in the eighteen factories in Egypt.

\section{Theoretical Framework}

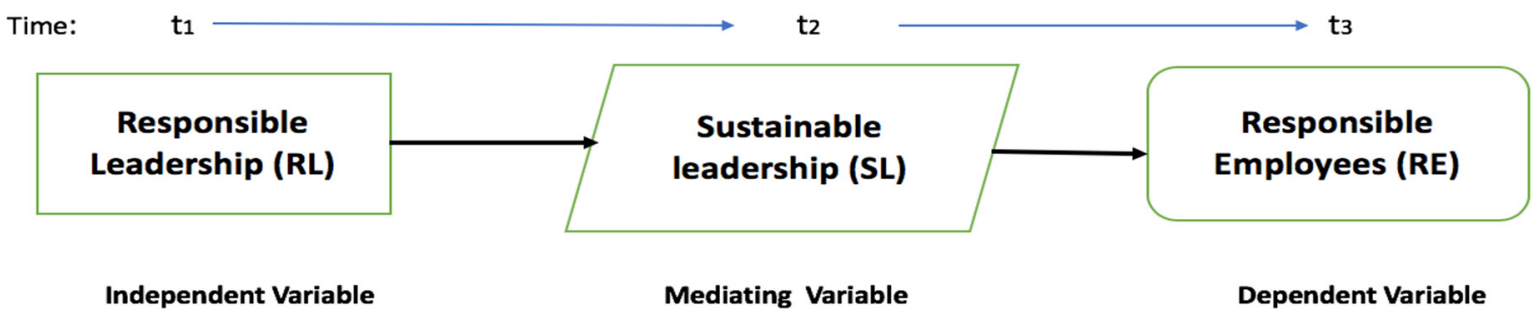

Figure 1. The proposed model

\subsection{Responsible Leadership (RL)}

Responsible Leadership (RL) theory is a multilevel response to deficiencies in existing leadership frameworks and theories. This theory is in response to high-profile scandals on an individual, organisational and systematic level; and to new and emerging social, ethical, and environmental challenges in an increasingly connected world. (Nicola Pless and Thomas Maak, 2011). They focus more on the responsibilities that leaders have in relation to several stakeholder groups, therefore this relationship is "the Centre of leadership" (Maak and Pless 2006b, p. 39),

previous theory and framework: First Module: Multiple Levels were developed by Christof Miska and Mark E. Mendenhall in 2018. The model maps multiple levels of analysis. The present RL models concentrate on three levels: (1) micro-level, which focuses on individual business leaders, (2) meso-level, which focuses on groups and corporate strategy within an organizational context level, (3) macro-level which focuses on culture, institutions and society, and (4) cross-level which focuses on several relationships and interactions between and among levels of analysis. (Miska \& Mendenhal, 2018).

Second Module: Christof Miska \& Christian Hilbe \& Susanne Mayer in 2014 developed an RL model based on three comprehensive theoretical perspectives on which to view the RL concept. These perspectives, based on research, include three main diminutions which have been reviewed by other researchers: (1) stakeholder views (Maak and Pless 2006, 2009; Stahl et al. 2013), which builds on the theory of stakeholders (Freeman et al. 2004; Hill and Jones 1992) and the conceptual framework of RL which is based on a broad array of different stakeholders and focuses on relational and ethical understanding; (2) agent views (Friedman 1970, 2007; Friedman and Fried- man 2002) which builds on the assumptions that considered business leaders' performance as owners of businesses to the individual they are mostly responsible for (Jensen and Meckling 1978; Ross 1973); and (3) converging views (Porter and Kramer 2006; Waldman and Galvin 2008; Waldman and Siegel 2008) which attempt to merge stakeholder and agent perspectives along with the logic of 'doing well by doing good.' that much literature refers to as good management. This orientation toward RL attempts to reconcile environmental, economic and social responsibilities within the strategic perspective. A clear fundamental commonality key in all three levels is the assumption that managers have the freedom of making decisions in their work roles (Carroll \& Shabana 2010).

Third Module: In 2012, Pless, Maak, and Waldman developed a model of RL which outlines four main approaches to the RL phenomenon based on the scope of constituent groups. This requires that managers focus on their organisation, as well as the accountability of managers toward other shareholders and the owners of the business. Based on their research, they developed four different orientations/approaches which are: (1) traditional economists that focus on short-term economic values and the orientations of share-holder; (2) opportunity seekers, that focuses on engaging in corporate responsibility (CR) activities for instrumental reasons; (3) integrators that focus on profit as the result of the social responsibilities for which the business has been conducted; and the last one (4) idealists that hold a wider and larger perspective on their business responsibilities (including social and environmental challenges), often embedded and associated with strong ethical, spiritual and religious considerations. 
Fourth Module: De Bettignies in 2014 has developed Five Dimensions of Responsible Leadership, his model was depended on a practical level with numerous of business leaders over many years, he claims that there are five dimensions for RL style, these dimensions consisted of Awareness, Vision, Imagination, responsibility and action, and in each dimension, there is three levels are Individual, organisational and Social level.

Fifth Module: In the AOM conference 2019 at Bled, Slovene a new dimensional levels module has been presented by Safaa Shaaban (2019) Suggested various levels of logical framework/ dimensions (1) personal level, which focuses on the personality traits and behavior level of individual leaders (2) individual-level, focuses on individual or followers interact and react to responsible leaders (3) organizational level, with a focus on organizational context, groups, and corporate strategy; (4) community level, with a focus on CSR, institutions, culture, and society; and (5) mixed level, cross with a focus on various linkages and interactions among and between the different previous levels of analysis.

\subsection{Sustainable Leadership (SL)}

Sustainable Leadership reflects an emerging purposeful consciousness among people who are choosing to live their lives and lead organisations in ways that account for their footprint on the earth, society and the health of a global economy (Ferdig, 2007). Sustainable Leadership defining according to the Sustainability Leadership Institute (2011) as sustainability leaders as individuals who are compelled to make a difference by deepening their awareness of themselves in relation to the world around them (SLI, 2011), its depend on how leaders espouse innovatively and creativity in thinking; seeing, and interacting which lead to a sustainable solution. The SL is the one who motivates employees toward supports sustainability action in a way of a better world in present and future (Visser \&Courtice, 2011). Nevertheless, SL leaders' point of view is to create a sustainable organisation is throughout to be more environmentally oriented rather than to practices in the usual business way (Šimanskiené and Župerkiené, 2014). Assessing and raising the awareness of the principles of sustainability of $\mathrm{RL}$ is by considering responsibility towards individual, groups, and organisations, as well as the personal level of leaders involved in the transformational process. According to Zulkiffli and Latiffi in (2016), they defined SL as "an ability to influence and motivate individual, groups, organisation and society by assessing sustainability knowledge into their principles without neglecting experience from the past, so that it can be improved continuously either in present also in future". (Zulkiffli \& Latiffi, 2016, p. 2).

The main elements of SL have been recognized in 2003 by the education sector in the statues, it is only focusing on the elementary and high school and not further, also the elementary and high school has to fail to attract good leaders (Hargreaves \& Fink, 2006). Therefore, they have developed SL models as a tool for leadership capacity inside organisations which will provide good values of profit to be able to reach it. There is still a need for research into this area (Stephens \& Graham, 2010). Hence, the SL concept is progressively dispersal among different industries. Furthermore, sustainability in business organisations has to go further than the traditional method of being 'green' and 'socially responsible' to normal business day-to-day (Kantabutra \& Saratun, 2013). Avery (2005) identified SL 19 elements of leadership practices differentiate from Rhineland and Anglo-US approaches. The approach of A Rhineland is originally the concepts of the economic model is Germany and the country around it. Meanwhile, the Anglo-US approach is focused on outlining the principles of business culture in the United States and the United Kingdom. there is a big difference between these two models in business culture within the project management perspectives.

\subsection{Responsible Employee (RE)}

The majority almost all the literature discussed the responsibility on the level of employer and employee from the concept of corporate social responsibility, however, responsibility as a concept with human resources is might be bigger certainty activity run by the HR-related to the community, the employee needs to be responsible towed their community as representative for their organisation same as human and responsible inside their originations, in their home as responsible. Let's have a look at the concept of responsiblity for different other views.

The root of responsibility is "respons" and the stem is "responsib" which are derived from Response. According to CognFit 2019, the definition of a responsible person is "Becoming a responsible person means being able to consciously make decisions, conduct behaviors that seek to improve oneself and/or help others. Most importantly, a responsible person accepts the consequences of his or her own actions and decisions. "

When searching the term of Responsibility, I found that the term is very widely explain used. The only generic definition is related to Ieraci (2007) gave an editorial perspective in a peer-reviewed journal, and while it did not actually define the terms, it lists key concepts relating to responsibility as trust, capability, judgement and choice. Cornock (2011: 690) also says "responsibility means to be responsible for an act one undertakes, while 
accountability simply means to be called to account".

The only measurement developed by Jackson, wall, and Davids (1993). Assesses the concept of responsibility is measuring the extent of job control, cognitive demand, and production responsibility an employee experiences in a job. The measuring scale covers timing control which defined as "the extent to which a job gives the employee the freedom to determine the scheduling of his or her work behavior" (Fields, D. 2013: 96). The second component is method control define as "the extent to which an employee has the freedom to choose how to carry out tasks" (Fields, D. 2013: 97). Cognitive demand is also assessed on two dimensions, first, one is monitoring demand, defined as "the extent to which a job requires an employee to perform passive monitoring tasks", the second one is problem-solving demand, defined as "the extent to which a job involves active, cognitive Processing to prevent or detect error" (Fields, D. 2013: 97). The last component is Production responsibility is defined as "the extent to which job involves responsibility for avoiding lost output and damage to expensive equipment" (Fields, D. 2013: 97).

\section{Research Aims and Hypotheses}

The current research proposes that the experience of the Sustainable Leadership triggers Responsible Leadership and this, in turn, increases the concept of Responsible Employees. The study. also proposes that Sustainable Leadership will affect the relationship between Responsible Leadership and Responsible Employees.

To achieve this objective of this study, the following hypotheses will be examined:

H1: Sustainable Leadership (RL) fully Mediating the relationship between Responsible Leadership and Responsible Employees

H2: Sustainable Leadership (RL) Partially Mediating the relationship between Responsible Leadership and Responsible Employees

\section{Methodology}

\subsection{Piloting the Study}

As a preliminary step, in-depth focuses group discussion interviews with a sample of factories staff as a sample of the target population have been conducted to check the importance of the research variables to the targeted population. 40 face to face interviews were conducted with factories staff members (engineering, Deputy CEO, Chemists, accounting and finance head of department and R\& D) in 18 factories located in Egypt. These interviews focused on two main points. First one, to explain and clarify the research objectives and main concepts. Second, to reveal the importance of the research objectives from ministry and Authority new strategy and new allocation for future leaders' perspectives.

\subsection{Population and Sample}

The main target group in this study were the young generation in leading posts in Military production factories in Egypt, these groups were targeted for empowerment by leadership program which targeted different style of leadership. Age from 30 to 45 . Mixed men and women. The survey was distributed on 400 employees, only 250 responded.

\subsection{Instrument and Measurement}

The questioners included 4 sections; the first part covered the demographic characteristics of the respondents. The second section measuring Responsible Leadership including 16 statements adapted from Voegtlin, Ch. (2011). The third section measuring the Sustainable Leadership adapted from Fernandez, A.; Kullu, F. D. and Shankar, R. (2019) including 53 statements. the fourth section measuring the responsible employee taken from Jackson, P. R., Wall, T. D., Martin, R., \&Davids, K. (1993) including 22 statements. All responses ranged from (1) Not at all; (2) Once in a while; (3) sometimes; (4) Fairly often; (5) Frequently if not always on a 5-point Likert Scale. The survey was translated into Arabic version in addition to the English, so the question was in English and Arabic.

\subsection{Reliability and Validity Analysis and Descriptive Statistics}

To test the internal consistency of the subscales Cronbach's coefficient was used for the data collected and the reported Cronbach's alpha coefficient is reasonably reliable (above 0.6 ). table 2 shows reliability results from the used scales. 
Table 1 . Reliability test for all variables

\begin{tabular}{llll}
\hline Scale & Responsible Leadership $(\boldsymbol{R L})$ & Sustainable Leadership $(\boldsymbol{S L})$ & Responsible Employee $(\mathrm{RE})$ \\
\hline Alpha & .828 & .975 & .758
\end{tabular}

Validity was examined by a panel of 10 experts ( 5 academics and 5 from civilians working in the military factories). The panel concluded that the used instrument is clear and complies with the Egyptian culture and the military factories environment.

Table 2. Descriptive statistics, correlation coefficients and reliability of the study variables

\begin{tabular}{llllll}
\hline Correlations & Mean & Std. Deviation & RL & SL & RE \\
\hline Responsible Leadership (RL) & 55.9760 & 8.92671 & & & $.717^{* *}$ \\
Sustainable Leadership (SL) & 196.8240 & 37.23152 & 1 & $.421^{* *}$ \\
Responsible Employees (RE) & 83.5000 & 8.56829 & $.421^{* *}$ & 1 \\
\hline
\end{tabular}

Note. **. Correlation is significant at the 0.01 level (2-tailed).

To test the validity of the use measures, two steps that take place are; first, the four-part questionnaire was reviewed and revised by a panel of 10 academics and experts who assessed the contents of the four parts and evaluated according to the Egyptian culture and context. The comments of the academics and experts are indicated and approved that theses questionnaires are valid and culturally fit. Second, a confirmatory factor analysis, using AMOS 20, was conducted to confirm the factor structure of Scale used to the target groups as shown in the table 2 .

As table 2 shows that the relationship between RL and SL is strongly correlated and significant. However, the relationship between RL and RE is significant but not strong.

\subsection{Statistical Analysis Results and Findings}

In testing the first Hypotheses, assuming that Sustainable Leadership mediate the relationship between Responsible Leadership and Responsible Employees

Table3. Model Summary

\begin{tabular}{lllll}
\hline Model & R & R Square & Adjusted R Square & Std. Error of the Estimate \\
\hline 1 & $.257^{\mathrm{a}}$ & .066 & .062 & 8.29749 \\
2 & $.426^{\mathrm{b}}$ & .181 & .174 & 7.78511 \\
\hline
\end{tabular}

a. Predictors: (Constant), RL.

b. Predictors: (Constant), RL, SL.

Table 4. ANOVA ${ }^{\mathrm{a}}$

\begin{tabular}{lllllll}
\hline Model & & Sum of Squares & df & Mean Square & F & Sig. \\
\hline 1 & Regression & 1206.120 & 1 & 1206.120 & 17.519 & $.000^{\mathrm{b}}$ \\
& Residual & 17074.380 & 248 & 68.848 & & \\
& Total & 18280.500 & 249 & & & \\
& Regression & 3310.358 & 2 & 1655.179 & 27.310 & $.000^{\mathrm{c}}$ \\
& Residual & 14970.142 & 247 & 60.608 & & \\
& Total & 18280.500 & 249 & & & \\
\hline
\end{tabular}

\footnotetext{
a. Dependent Variable: RE.

b. Predictors: (Constant), RL.

c. Predictors: (Constant), RL, SL.
} 
As it is shown from the previous results and tables above that the regression coefficient of the Responsible Leadership was highly or double increase when Sustainable Leadership was entered, therefore it can be concluded that the relationship fully mediates the relationship between Responsible Leadership and Responsible Employees. The result was confirmed using Hierarchal multiple regression as ( $\mathrm{R}$ and $\mathrm{R}$ square) increased to the double as shown in table 4 . Then the first hypothesis is accepted.

Tables 3 and 4 show that $\mathrm{R}$ and $\mathrm{F}$ have increased by nearly double from the first step to the second step which shows that SL fully mediates the relationship between RL and RE.

Table 5. Coefficients

\begin{tabular}{|c|c|c|c|c|c|c|}
\hline \multirow[b]{3}{*}{ Model } & & \multirow{2}{*}{\multicolumn{2}{|c|}{ Unstandardized Coefficients }} & \multirow{2}{*}{$\begin{array}{l}\text { Standardized } \\
\text { Coefficients }\end{array}$} & & \multirow[b]{3}{*}{ Sig. } \\
\hline & & & & & & \\
\hline & & $\mathrm{B}$ & Std. Error & Beta & $\mathrm{t}$ & \\
\hline \multirow[t]{2}{*}{1} & (Constant) & 69.699 & 3.339 & & 20.876 & .000 \\
\hline & $\mathrm{RL}$ & .247 & .059 & .257 & 4.186 & .000 \\
\hline \multirow[t]{3}{*}{2} & (Constant) & 66.413 & 3.182 & & 20.872 & .000 \\
\hline & RL & -.089 & .079 & -.093 & -1.120 & .264 \\
\hline & SL & .112 & .019 & .487 & 5.892 & .000 \\
\hline
\end{tabular}

a. Dependent Variable: RE.

The multiple regression analysis indicates that there is a significant interaction between Responsible Leadership and Sustainable Leadership that affect Responsible Employees which accept hypothesis one and rejected hypothesis two. Table 5 shows that the relationship between RL and RE is significant but not strong. However, when SL enters the analysis it shows very strong relationships and significance. Therefore, the SL fully mediates the relationship between RL and RE.

\subsection{The Result of Structure Equation Model}

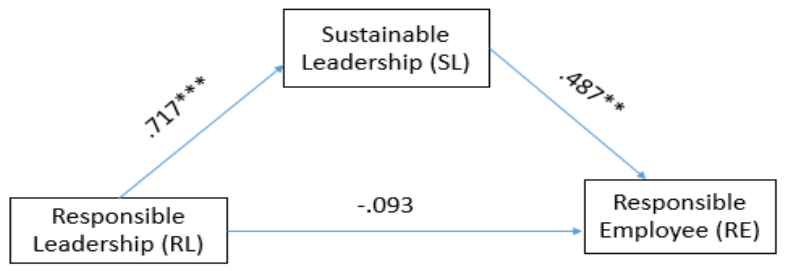

Figure 2. Structural equation modelling

Table 6. Fit indices for the factor structures of the used instruments

\begin{tabular}{ll}
\hline Total Effect $=.257$ & GFI $=.98$ \\
\hline Direct Effect $=-.093$ & AGFI $=.97$ \\
Indirect Effect $=.335$ & CFI $=.96$ \\
& NFI $=.98$ \\
& RMSEA $=.05$ \\
\hline
\end{tabular}

Table 7. Regression weights: (Group number 1 - Default model)

\begin{tabular}{llllllll}
\hline & & & Estimate & S.E. & C.R. & P & Label \\
\hline SL & $<---$ & RL & 2.992 & .184 & 16.253 & $* * *$ & \\
RE & $<---$ & SL & .112 & .019 & 5.916 & $* * *$ & \\
RE & $<---$ & RL & -.089 & .079 & -1.125 & .261 & \\
\hline
\end{tabular}


Table 8. Standardized Regression Weights: (Group number 1 - Default model)

\begin{tabular}{llll}
\hline & & & Estimate \\
$\mathrm{SL}$ & $<---$ & $\mathrm{RL}$ & .717 \\
$\mathrm{RE}$ & $<---$ & $\mathrm{SL}$ & .487 \\
$\mathrm{RE}$ & $<---$ & $\mathrm{RL}$ & -.093 \\
\hline
\end{tabular}

It is shown from the previous results that all the questionnaire variables have a significant relationship. The fit indices these factors structure is shown in table (6), (7) and (8).

\section{Discussion}

Understanding and highlighting the concept of Responsible Leadership and Sustainable Leadership importance and essential issues that have been discussed recently in the literature as part of the economic development and sustainability. Also, the concept of Responsible Employees, although it is important, there is a lack in the literature discussing this concept as well. This research is lined at feeding the literate with more research-related and supporting to the concept of responsible leadership and Sustainable Leadership, furthermore, build a basis for the concept of Responsible Employees as there is a big lack in the literature about this concept. However, the only link to Responsible Employees is linked to CSR within the organisations as it has been mentioned by Bombiak and Marciniuk-Kluska (2019). Bombiak in 2019 "There has been increased interest over recent years in socially responsible human resource management (SRHRM) oriented at developing good relations with employees as a function fostering sustainable organization-building. This is a consequence of our awareness of the fact that employees and personnel processes play a vital role in translating the policy of sustainable development into practice" (Bombiak and Marciniuk-Kluska 2019: 2).

The result indicates that employees in the Egyptian factories are experiencing a relatively high level of responsibility under the Responsible Leadership, and Sustainable Leadership relatively mediates at a high level (fully mediate the relationship).

The Correlation analysis revealed the existence of a strong significant relationship between Responsible Leadership (RL) and Sustainable Leadership (SL) is strongly correlated and significant. However, the relationship between RL and Responsible Employees (RE) is significant also but not strong. In the studied sample the respondents had relatively long experience in general.

The results supported the relationship between Responsible leadership\& Sustainable Leadership and Responsible Employees. This study proposed the mediating role of Sustainable Leadership in the relationship between Responsible Leadership and Responsible Employees. According to the results, the regression coefficient of Responsible Employees was slightly and significantly change the relationship in B from (.247) to (-.089) to (.112); R increased to the double from (.257) to (.426) and R. Square from (.062) to (.174) when Sustainable Leadership was entered in the regression model. This means that when Sustainable Leadership (SL) exists, the effect of Responsible Leadership on affective Responsible Leadership is established and increased to the double, but the relationship remains significant, which indicates that the Sustainable Leadership is fully mediating the relationship. This mediation role was confirmed by AMOS (structural Equation Module). This study is the first study conformant of this relationship between its variables and to confirm the existing concept of Responsible Leadership using Responsibility Scale by Jackson, P. R., Wall, T. D., Martin, R., \&Davids, K. (1993).

\section{Research Implication and Practice}

This study result has many crucial practical implications: First, the Responsible Leadership concept is a newly discussed issue that requires more study on the concept itself and the supported issues related to it such as, Responsible Employees and follower is an essential concept this paper raised. Personality traits required for this kind of leaders responsible to implement this kind of leadership approach. Sustainability leader (SL) are believed to strive to reach the sustainability goals based on their beliefs, this might reveal their deficiencies (Courtice, 2011). For example, Sincerity and Modesty were found to predict ethical attitude in leadership in one study of Žiaran (2015).

Second, then there is the need of understanding between business leaders for a better understanding of the leadership and leaders' roles and the supported other leadership approach's to Responsible Leadership, Sustainable Leadership is an essential approach supported the Responsible Leadership to create the Responsible Employees, which we proved in this study. 
Third, businesses need to be able to meet updated world market needs for sustainability and they need to consider the Responsible Leadership and Sustainable Leadership in their leadership and orientation within their organisation to reach with their employee to be responsible to support their organisation to sustain responsibly. The employees' cultivation of sustainable is to protect the longevity of business while driving it toward future success, which, when your team isn't on board with the mission, the whole company lags behind. Culture suffers.

One of the most important companies aims is to focus on building a sustainable workforce to be able to connect and produce results authentically and successfully. The sustainability of the company is typically keen on its impact on the community locally and globally, however, sustainability is about to start with the people who are behind the scenes. This is the matter of uniting them to create a better work culture, work-life balance and contributions to their organisation, community the whole world (William Craig, 2018)

These study results contributed to literature first by highlighting the role of Responsible Employees a new concept introducing to the literature and its relation to responsible leadership. Second by emphasizing the mediation role of Sustainable Leadership in the relationship between Responsible Leadership and Responsible Employees. Theses study result also have several theoretical implications; first, that the explained concept of Responsible Leadership and Sustainable Leadership, also introducing the concept of Responsible Employees is considered as one of the most important points that should be raised in the literature as this concept is absent in the literature.

\section{Conclusion}

This study targeted to enrich our understanding of the relationship between responsible leadership (RL) and Responsible Employees (RE) by examining the mediation effect of Sustainable Leadership. The results revealed that Sustainable Leadership serve as fully mediating in the relationship between Responsible Leadership and Responsible Employees.

The first hypotheses, proposing a fully mediating role of the Sustainable Leadership was supported by this study.

The second hypotheses were Sustainable Leadership as partially mediating the relationship between Responsible Leadership and Responsible Employees. The proposed structural model was tested using SEM, the model for indices supporting the proposed relationship between the Responsible Leadership and Responsible Employees.

\section{Future Research}

These study results are subject to some limitation such as the first one is the scope of this study and is limited to these kinds of employees working in these factories and this age, as the majority of top management with a military background. Second, the research sample 250 respondents and the type of sample may also limit the generalizability of the study results. So, future research is needed to address the effects of Sustainable Leadership as a mediator on Responsible Employees as a new concept. Responsible Employees need to be investigated as a dependent variable and Responsible Leadership and Sustainable Leadership as independent variables.

\section{References}

Avery, G. C. (2005). Leadership for Sustainable Futures: Achieving Success in a Competitive World. Edward Elgar, Cheltenham.

Avery, G., \& Bergsteiner, H. (2011a). Sustainable leadership practices for enhancing business resilience and performance. Strategy \& Leadership, 39(3), 5-15.

Bombiak, E., \& Marciniuk-Kluska, A. (2019). Socially Responsible Human Resource Management as a Concept of Fostering Sustainable Organization-Building: Experiences of Young Polish Companies.

Carroll, A. B., \& Shabana, K. M. (2010). The business case for corporate social responsibility: A review of concepts, research and practice. International Journal of Management Reviews, 12(1), 85-105.

Cogn Fit. (2019). Retrieved January 1st, 2020, from https://blog.cognifit.com/responsibility/

Cornock, M. (2011). Legal definitions of responsibility, accountability and liability. Nursing Children \& Young People, 23(3), 25-26.

Craig, W. (2018). The importance of creating sustainable employees in the workplace, Forbes. Retrieved from https://www.forbes.com/sites/williamcraig/2018/06/19/the-importance-of-creating-sustainable-employees-i n-the-workplace/\#7be5d5ff7285

De Bettignies, H. (2014). Five Dimensions of Responsible leadership. France: INSEAD Knowledge, Fontainebleau. 
Demaid, A., \& Quintas, P. (2006). Knowledge across cultures in the construction industry: sustainability, innovation and design.

Fable, N., Jorna, R., \& Van Engelen, J. (2005). The sustainability of sustainability - a study into the conceptual foundations of the notion of the notion of sustainability. Journal of Environmental Assessment Policy \& Management, 7(1), 1-33.

Ferdig, M. A. (2007). Sustainability leadership: co-creating a sustainable future. Journal of Change Management, 7, 25-35.

Fernandez, A.; Kullu, F. D., \& Shankar, R. (2019). The multidimensional Sustainable Leadership Competencies Scale. Factor structure, reliability and validity, BAM2019 conference proceedings.

Fields, D. L. (2013). Taking the Measure of work: A guide to Validated Scales for Organizational Research and Diagnosis. Information Age Publishing Inc.

Freeman, R. E., Wicks, A. C., \& Parmar, B. (2004). Stakeholder theory and "the corporate objective revisited". Organization Science, 15(3), 364-369.

Friedman, M. (1962). Capitalism and freedom. Chicago: University of Chicago Press.

Friedman, M. (1970). The social responsibility of business to increase its profits. New York Times, 13, 122-126.

Hargreaves, A., \& Fink, D. (2006). Sustainable leadership. San Francisco: Jossey-Bass.

Hill, C. W. L., \& Jones, T. M. (1992). Stakeholder-Agency Theory. Journal of Management Studies, 29, 131-154. http://dx.doi.org/10.1111/j.1467-6486.1992.tb00657

Ieraci, S. (2007). Responsibility versus accountability in a risk-averse culture. Emergency Medicine Australiasia, $19,63-64$

Jackson, P. R., Wall, T. D., Martin, R., \& Davids, K. (1993). New measures of job control, cognitive demand, and production responsibility. Journal of Applied psychology, 78(5), 753-762

Jensen, M. C., \& William, H. M. (1978). Can the Corporation Survive? Financial Analysts Journal.

Kantabutra, S., \& Saratun, M. (2013). Sustainable leadership: honeybee practices at Thailand's oldest university. International Journal of Educational Management, 27(4), 356376.

Maak, T., \& Pless, N. (2006). Responsible Leadership in a Stakeholder Society - A Relational Perspective. J Bus Ethics, 66, 99-115. https://doi.org/10.1007/s10551-006-9047-z

Miska, C., \& Mendenhall, M. (2018). Responsible Leadership: A Mapping of Extant Research and Future Directions. Journal of Business Ethics, 148. https://doi.org/10.1007/s10551-015-2999-0

Miska, C., Stahl, G., \& Mendenhall, M. (2013). Miska, C., Stahl, G. K. \& Mendenhall, M. (2013). Intercultural competencies as antecedents of responsible global leadership. European Journal of International Management, 7, 550-569. https://doi.org/10.1504/EJIM.2013.056477

ourtice, P. (2011). The Challenge to Business as Usual. The University of Cambridge Programme for Sustainability Leadership.

Pakir, A. H. K. et al. (2012). Sustainable Housing Development and Leadership: A Review. Australian Journal of Basic and Applied Sciences, 6(12), 385-395.

Pless, N. M., \& Maak, T. (2011). Responsible Leadership: Pathways to the Future. J Bus Ethic, 98, 3-13.

Porter, M. E., \& Kramer, M. R. (2006). Strategy \& society: The link between competitive advantage and corporate social responsibility. Harvard Business Review, 84(12), 78-92.

Ross, S. A. (1973). The Economic Theory of Agency: The Principal's Problems. American Economic Review LXII, 134-139.

Shaaban, S. (2019). Suggested Conceptual Logical framework, and Dimensions for Responsible Leadership. Responsible leadership in rising ecnomics Conference. Bled, Slovenia, conference proceedings.

Šimanskienė, L., \& Župerkienè, E. (2014). Sustainable leadership: The New Challenge for Organisations. Knowledge Economy Forum, 8193.

Stephens, J., \& Graham, A. (2010). Toward an empirical research agenda for sustainability in higher education: Exploring the transition management framework. Journal of Cleaner Production, 611-618. 
Sustainability Leadership Institute. (2011). Retrieved August 1st, 2015, from http://sustainabilityleadershipinstitute.org/

Sustainability Leadership Institute. (2011). Retrieved August 1st, 2015, from $\mathrm{http}: / /$ sustainabilityleadershipinstitute.org/

Visser, W., \& Courtice, P. (2011). Sustainability Leadership: Linking Theory and Practice.

Voegtlin, Ch. (2011). Development of a Scale Measuring Discursive Responsible Leadership. Science+Business Media B.V.

Waldman, D. A., \& Galvin, B. M. (2008). Alternative perspectives of responsible leadership. Organizational Dynamics, 37(4), 327-341.

Waldman, D. A., \& Siegel, D. (2008). Defining the socially responsible leader. The Leadership Quarterly, 19(1), $117-131$.

Yılmaz, M., \& Bakış, A. (2015). Sustainability in Construction Sector. World Conference on Technology. Innovation and Entrepreneurship, 2253-2262.

Žiaran, P. (2015). Humility and Self-esteem as Key Predictors of Ethical Attitude in Leadership. Procedia Economics and Finance, 34, 689-696.

Zulkiffli, N. A., \& Latiffi, A. A. (2016). Theoretical Review on Sustainable Leadership (SL). MATEC, IBCC, Web of Conferences, 66, 00045. https://doi.org/10.1051/matecconf/20166600045

\section{Copyrights}

Copyright for this article is retained by the author(s), with first publication rights granted to the journal.

This is an open-access article distributed under the terms and conditions of the Creative Commons Attribution license (http://creativecommons.org/licenses/by/4.0/). 